\title{
Acceptance of COVID-19 Vaccine and Determinant Factors Among Patients with Chronic Disease Visiting Dessie Comprehensive Specialized Hospital, Northeastern Ethiopia
}

\author{
Gete Berihun (ID) \\ Zebader Walle (iD) ${ }^{2}$ \\ Leykun Berhanu (D) \\ Daniel Teshome (1D ${ }^{3}$ \\ 'Department of Environmental Health, \\ College of Medicine and Health Sciences, \\ Wollo University, Dessie, Ethiopia; \\ ${ }^{2}$ Department of Public Health, College of \\ Health Sciences, Debre Tabor University, \\ Debre Tabor, Ethiopia; ${ }^{3}$ Department of \\ Anatomy, College of Medicine and Health \\ Sciences, Wollo University, Dessie, \\ Ethiopia
}

Background: Despite the implementation of different COVID-19 prevention measures, the incidence of the disease continues to rise. Hence, vaccines have been taken as the best option for controlling the transmission of the disease. Although the approved COVID-19 vaccines have proven to be safe and effective, multiple beliefs and misconceptions still exist influencing its acceptance.

Objective: To assess the acceptance of the COVID-19 vaccine and determinant factors among chronic patients visiting Dessie Comprehensive Specialized Hospital, Northeastern Ethiopia.

Methods: Institution-based cross-sectional study design was used among patients with chronic diseases visiting Dessie Comprehensive Specialized Hospital from May 1 to 20, 2021 using a consecutive sampling technique. Binary logistic regression analysis using crude odd ratio (COR) and adjusted odd ratio (AOR) was performed to assess the association between independent and dependent variables. Variables having p values of less than 0.05 at the $95 \%$ confidence interval (CI) were considered as factors of COVID-19 vaccine acceptance.

Results: A total of 416 respondents participated in the survey, with a response rate of $98.6 \%$. About $59.4 \%$ of the respondents were willing to accept the COVID-19 vaccine. Participants who had health insurance (AOR=1.812; 95\% CI: 1.703-3.059), knew anyone diagnosed with COVID$19(\mathrm{AOR}=2.482$; 95\% CI: 1.427-4.317), having good knowledge of the COVID-19 vaccine (AOR=6.890; 95\% CI: 3.900-120.17), and having a positive attitude towards COVID-19 vaccine $(\mathrm{AOR}=7.725 ; 95 \% \mathrm{CI}: 4.024-14.830)$ were factors affecting the acceptance of COVID-19 vaccine. Conclusion: The acceptance of the COVID-19 vaccine was low. Use of health insurance, knowing anyone who had been diagnosed with COVID-19, knowledge, and attitude towards the COVID-19 vaccine were factors of COVID-19 vaccine acceptance. Healthcare professionals should conduct continuous awareness creation campaigns on the importance of the COVID-19 vaccine, safety, and its efficacy. Further studies like longitudinal and qualitative studies should be conducted to identify additional barriers to vaccine acceptance particularly in high-risk groups.

Keywords: COVID-19, vaccine, acceptance, chronic patients, Ethiopia

\section{Introduction}

Coronavirus disease (COVID-19) has caused a global health crisis since December 2019, is caused by Severe Acute Respiratory Syndrome Coronavirus-2 (SARS-CoV-2). ${ }^{1-4}$ The disease was initially reported in China and then declared as a Public Health Emergency of International Concern by the World Health Organization (WHO) on January 31, 2020, and a global pandemic on March 31,
Correspondence: Gete Berihun Email geteberihun@gmail.com 
$2020 .^{5-8}$ The pandemic has affected 223 countries across the globe ${ }^{9}$ and a total of 174,539,625 confirmed cases and $3,756,185$ deaths were reported as of June 9,2021 . $^{10}$ The first confirmed cases of COVID-19 in Ethiopia was reported on March 13, 2020. ${ }^{11,12}$ Since then, a total of 373, 398 confirmed cases of COVID-19 and 4226 deaths were reported as of June $9,2021 .^{12}$

The COVID-19 pandemic has disrupted the world economy, the health systems, and the quality of life of survivors mainly in developing countries. ${ }^{13,14}$ The majority of infections with COVID-19 cause a mild form of infection. But, those elder and people with comorbidities, including cardiovascular, respiratory diseases, and diabetes are five times more likely to have an increased risk of severe illness and death. ${ }^{15,16}$ The impacts of COVID-19 on patients with chronic disease are not only restricted on direct effect but also in an indirect manner. Resources at all levels have been shifted away from patients with chronic diseases management and prevention to pandemic management particularly, in low and middle-income countries, including Ethiopia. ${ }^{17}$

The world has implemented different COVID-19 prevention measures, like quarantine, restricted movement, nationwide lockdowns, ${ }^{15}$ handwashing with water and soap, keep respiratory hygiene, and use facemask. ${ }^{18,-20}$ Despite the implementation of these measures across the world, the burden of the pandemic is not significantly reduced. ${ }^{1}$ The health and economic burden of the pandemic prompted the need for timely and effective vaccine development. ${ }^{14}$ Hence, vaccination was considered as the best strategy for controlling the transmission of the disease. ${ }^{1}$ In May 2020, the 73rd World Health Assembly issued a resolution recognizing the role of extensive immunization as a global public-health goal for preventing, containing, and stopping transmission of SARS-CoV -2 . Globally, there are now more than 125 vaccine candidates, 365 vaccine trials ongoing, and 18 vaccines against COVID-19 approved by at least one country. ${ }^{21}$ Vaccine plays a vital role in reducing the infection of COVID-19, particularly among high-risk groups such as health care workers, the elderly, and individuals with chronic diseases. ${ }^{19}$ The vaccine has been shown to reduce infections even among individuals who are not vaccinated, through the development of herd immunity, if most of the population become vaccinated. ${ }^{22}$

Ethiopian health authorities choose to employ the Astra Zeneca COVID-19 vaccination through the COVAX Facility and Covishield vaccines since March 7, 2021.
Hence, Ethiopia received 2.184 million doses of COVID19 vaccination. The Ethiopian Ministry of Health officially launched the COVID-19 vaccine at a high-level national event held at Eka Kotebe COVID-19 Hospital, where front-line health workers were vaccinated to kick of the vaccination campaign. ${ }^{23}$ Health care professionals (HC), elderly, patients with chronic disease above the age of 55 years old are the prioritized populations for vaccination against COVID-19. Ethiopia has planned to vaccinate only $20 \%$ of the population until the end of $2021 .^{14,24,25}$

There is evidence that a significant portion of the population in many countries, may not be willing to get vaccinated against COVID-19. ${ }^{26}$ Misinformation and lack of confidence towards vaccines led to low acceptance. ${ }^{25}$ Vaccine hesitancy and resistance are major issues around the world, causing the WHO list it among the top ten health risks for $2019 .{ }^{20,23}$ Studies have revealed that the acceptance rate of COVID-19 vaccine in the United States of America (USA) $54 \%,{ }^{14}$ France $(71.6 \%),{ }^{27}$ USA $(57.6 \%),{ }^{22}$ Kuwait (83\%), ${ }^{28}$ Ethiopia (72.2\%), ${ }^{29}$ Ethiopia $(54.8 \%),{ }^{25}$ China $(84.3 \%),{ }^{30}$ Saudi Arabia $(64.9 \%),{ }^{31}$ Kenya $(61.33 \%),{ }^{32}$ China $(83.5 \%),{ }^{33}$ Turkey $(54 \%),{ }^{34}$ UK $(71.7 \%),{ }^{35}$ China $(91.3 \%),{ }^{36}$ Ecuador $(91 \%),{ }^{37}$ and France $(65.6 \%){ }^{38}$

Studies have also examined factors of willingness to get vaccinated against COVID-19 were perceived risk, sex, race/ethnicity, age vaccine safety, educational level, history of influenza vaccine, professions, vaccination history, religion, visits to high-risk areas, vaccination status of family members, side effects experienced after receiving other vaccines, information-seeking behaviors, trusting healthcare workers, income, adherence to COVID-19 government guidelines, living with children, unforeseen side effects. Perceived benefits, vaccine efficacy, marital status, perceiving a high risk of infection, vaccine price in decision-making, history of COVID-19 test, a high level of worry of contracting COVID-19, and believed that COVID-19 infection can be prevented with a vaccine were factors of COVID-19 vaccine acceptance. $^{14,22,25,27,28,30,32,33,37-39}$

In order to implement the most effective vaccination strategies, the prevalence of and determinant factors of vaccine accetance are crucial for Government and policymakers to address all barriers against COVID-19 vaccine acceptance. To date, there has been no prior study on COVID-19 vaccine acceptance among patients with chronic diseases. Therefore, this study was designed to assess the acceptance of the COVID-19 vaccine and 
determining factors among patients with chronic diseases visiting Dessie Comprehensive Specialized Hospital, Northeastern Ethiopia from May 1-20, 2021.

\section{Methods}

\section{Study Design, Period, and Setting}

Institution-based cross-sectional study design was conducted among 416 patients with chronic diseases who have visited Dessie Comprehensive Specialized Hospital from May 1-20, 2021. Dessie town is located in South Wollo Zone, Amhara region, Northeastern Ethiopia. The town is located in a mountainous setting, 401 kilometers north of Addis Ababa and 480 kilometers from Bahir Dar, the capital city of the Amhara Region. According to the record of the Health Management Information System of Dessie Comrhensive Specialized Hospital, more than 25,000 patients with chronic diseases were registered and attending in the hospital.

\section{Populations of the Study}

The source population of the study was all patients with chronic diseases who had visited Dessie Comprehensive Specialized Hospital, whereas the study population was all patients with chronic diseases who had visited Dessie Comprehensive Specialized Hospital during the data collection time, between May 1 to 20, 2021.

\section{Inclusion and Exclusion Criteria}

All patients with chronic diseases who were volunteer to participate were included in the study. Patients with chronic diseases under the age of 18 and those who were unable to respond owing to a severe illness were excluded from the study.

\section{Sample Size Determination and Sampling Technique}

The sample size was determined using the single population proportion formula ${ }^{18}$

$$
n=\frac{\left(Z_{\alpha / 2}\right)^{2} * p(1-p)}{d^{2}}
$$

$Z_{\alpha / 2}$ is the standard normal variable value at $(1-\alpha) \%$ confidence level ( $\alpha$ is 0.05 with $95 \% \mathrm{CI}, \mathrm{Z}_{\alpha / 2}=1.96$ ), an estimate of the proportion $(p)$ was considered as $50 \%$, and margin of error $(d) 5 \%$. To employ the maximum sample size, $50 \%$ of the study population was assumed to be vaccinated against COVID-19. Hence, the sample size becomes 384 , and adding of a $10 \%$ non-response rate, the final sample size became 422. The study subjects were chosen using a consecutive sampling technique.

\section{Study Variables}

The outcome variable of the study was the acceptance of the COVID-19 vaccine (yes/no options). The dependent variables were respondents' sociodemographic data (sex, marital status, age, religion, self-rated health status, educational level, average monthly income, occupation, residence, presence of health insurance, and duration of chronic illness, know anyone infected with COVID-19), the socio-political variable of the respondents, knowledge, and attitude towards COVID-19 vaccine.

\section{Operational Definitions}

COVID-19 vaccine acceptance was measured using "Yes" and "No" questions, respondents were asked "Are you willing to be vaccinated against COVID-19?"; Seven items were used to assess respondents' knowledge about the COVID-19 vaccine. Those who correctly answered the question received one point, while incrrect resnse was given zero values. Respondents who scored $70 \%$ and above were taken as having good knowledge while those who scored less than $70 \%$ were considered as having poor knowledge towards the COVID-19 vaccine. ${ }^{40}$

Eight items were used to assess the respondents' attitude on the COVID-19 vaccine. Those who agreed received 3 points, neutral 2 points, and disagreed got 1 point for positive questions and vice versa for negative quoted attitude questions. The respondents' attitudes ranged from 1 to 24, with a cutoff of greater than or equal to $70 \%$ (17-24) were considered as a positive attitude while less than $70 \%$ (17) were taken as having a negative attitude towards the COVID-19 vaccine. ${ }^{40}$

\section{Data Collection and Quality Assurance}

The data was collected using a pre-tested structured questionnaire, which was adapted from published papers. ${ }^{40-43}$ It consists of five sections including, socio-demographic characteristics of the participants and sources of information towards COVID-19 vaccine, knowledge about COVID-19 vaccine, attitude towards COVID-19 vaccine, socio-political factors, and acceptance of COVID-19 vaccine. The questionnaire was prepared in English language and translated to the local language (Amharic) and retranslated back to the English version to ensure consistency. The pre-test was conducted among 5\% of the 
sample size in Borumeda hospital to ensure the validation of the tool. Hence, amendment was done based on the feedback of the pre-test before the commencement of the final data collection. Training was given for the data collectors and supervisors on the aim of the study, clarity of the measuring tool, and ethical considerations. The data was collected from May 1 to 20, 2021 by three health officers and supervised by two master holders of Public Health experts. Before starting the analysis, $10 \%$ of the final sample size was used to check data entry errors.

\section{Statistical Analysis}

Data were entered into Epi-Data version 4.6 and exported to the Statistical Package for Social Science (SPSS) version 25.0 software for data cleaning and analysis. Frequency and percentage were used to describe the categorical variables whereas mean with standard deviation for continuous variables. Binary logistic regression analysis using bivariable analysis and multivariable analysis was used to determine the association between the dependent and the outcome variable of the study. In the bivariable analysis using crude odds ratio (COR) variables with $p$ values of less than 0.25 were retained for multivariable analysis. Then in multivariable analysis, $\mathrm{p}$ values of less than 0.05 at $95 \% \mathrm{CI}$ were taken as factors significantly associated with the acceptance of the COVID-19 vaccine. The multicollinearity among independent variables was checked using standard error at the cutoff value of -2 to +2 and none of the deendent variables . Furthermore, model fitness was checked using the Hosmer and Lemeshow test and we found a $\mathrm{P}$ value of 0.865 , which was fit.

\section{Ethical Consideration}

The stud was conducted following Helsinki Declaration. Ethical clearance was obtained from the ethical review committee of the College of Medicine and Health Sciences, Wollo University. Permission to conduct the study was obtained from Dessie Comprehensive Specialized Hospital. Before starting the data collection, the aim of the study was explained to the respondents. Verbal informed consent was obtained from participants who could not read and write, and the verbally informed consent process was approved by the ethical review committee of Wollo University, while written informed consent was btained from participants who can read and write. The confidentiality of the study particiants were ensured by aviding an identifier like name. Partication in the stud was based on vlunteer decision. Privacy was kept by taking the data anonymously, and also the participants had the right to be excluded from the study if they did not want to participate. Particiants have also told as the have the right to withdraw from the study at any stage.The data collection was conducted by applying the WHO recommended COVID-19 prevention measures such as wearing face masks, keeping social distancing, and using alcoholbased hand sanitizer.

\section{Results}

\section{Socio-Demographic Characteristics of Study Participants}

A total of 416 respondents participated in the study with a response rate of $98.6 \%$. About half 231 (50.4\%) of the respondents were females. The majority of the respondents were Muslims, college and above educational level, and housewives with a value of 202 (48.6\%), 123 (29.6\%), and 115 (27.6\%), respectively. Furthermore, half 215 (51.7\%) of the study participants had received necessary vaccines in their life before the occurrence of COVID-19. More than one quarter $111(26.7 \%)$ of the respondents were attending in the hospital due to respiratory diseases. Finally, less than ten percent $28(6.7 \%)$ of the respondents were current smokers during the data collection (Table 1).

\section{Sources of Information About COVID-19 Vaccine}

The current finding revealed that the majority 358 (86.1\%) of the participants used neighbors as sources of information towards the COVID-19 vaccine. Onethird $141(33.9 \%)$ of the participants used HCPs as sources of information about the COVID-19 vaccine. A lower number of respondents 84 (20.2\%) used newspapers as sources of information towards the COVID19 vaccine. Furthermore, less than half 189 (45.4\%) of them used social media as sources of information towards the COVID-19 vaccine. Less than half 192 (46.2\%) of the participants used radio and television as sources of information towards the COVID-19 vaccine (Table 2).

\section{Knowledge About COVID-19 Vaccine}

Less than two-thirds 261 (62.7\%) of the respondents had good knowledge about the COVID-19 vaccine. More than three-quarters $336(80.8 \%)$ of the respondents knew that COVID-19 is prevented through vaccine. About half $205(49.5 \%)$ of the respondents correctly 
Table I Socio-Demographic Characteristics of Patients with Chronic Disease Visiting in Dessie Comprehensive Specialized Hospital, Northeastern Ethiopia May I to 20, 202I

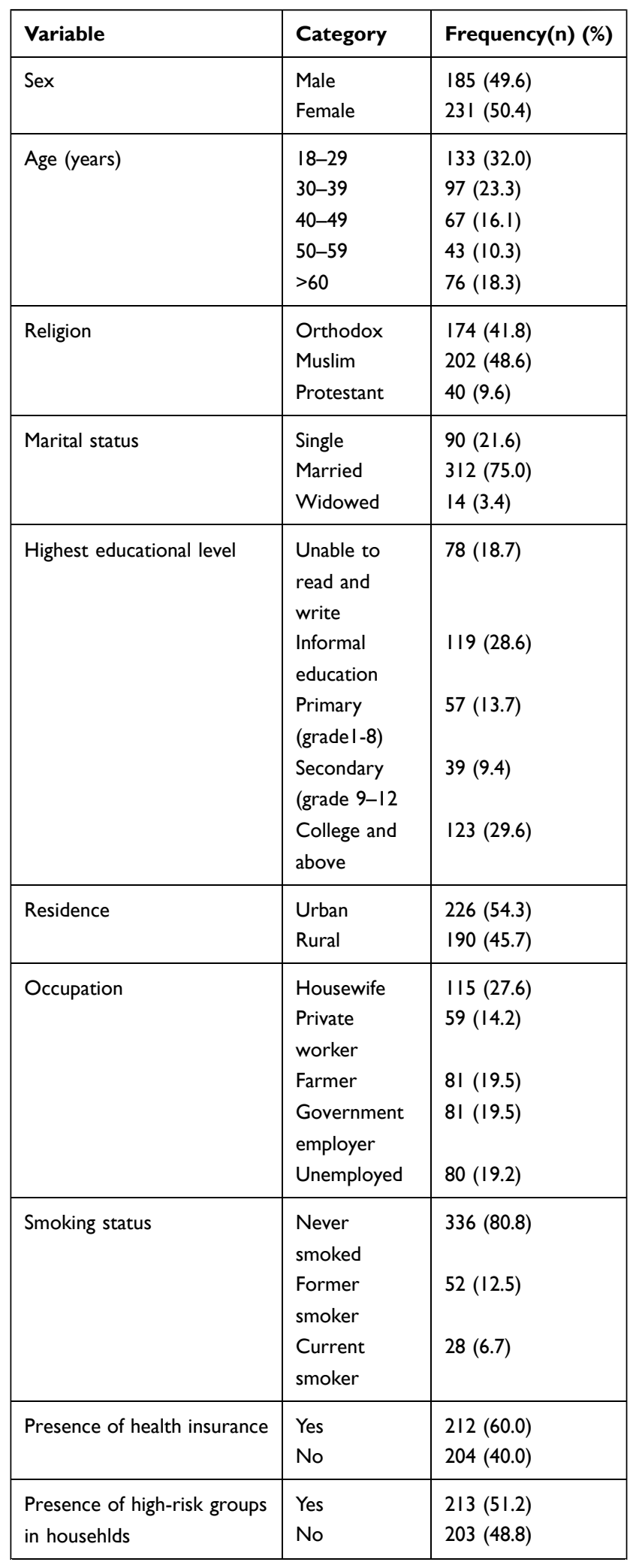

(Continued)
Table I (Continued).

\begin{tabular}{|c|c|c|}
\hline Variable & Category & Frequency(n) (\%) \\
\hline History of vaccine & $\begin{array}{l}\text { Yes } \\
\text { No }\end{array}$ & $\begin{array}{l}215(51.7) \\
201(48.3)\end{array}$ \\
\hline Travel history & $\begin{array}{l}\text { Yes } \\
\text { No }\end{array}$ & $\begin{array}{l}246(59.1) \\
170(40.9)\end{array}$ \\
\hline Average monthly income (\$) & $\begin{array}{l}\leq 37.5 \\
37.525-75 \\
\geq 75.025\end{array}$ & $\begin{array}{l}102(24.5) \\
218(52.4) \\
96(23.1)\end{array}$ \\
\hline Types of chronic illness & $\begin{array}{l}\text { Hypertension } \\
\text { Respiratory } \\
\text { disease } \\
\text { Diabetes } \\
\text { mellitus } \\
\text { HIV } \\
\text { Heart disease } \\
\text { Others* }\end{array}$ & $\begin{array}{l}62(14.9) \\
111(26.7) \\
86(20.7) \\
89(21.4) \\
55(13.2) \\
13(3.1)\end{array}$ \\
\hline $\begin{array}{l}\text { Duration of attending follow } \\
\text { up }\end{array}$ & $\begin{array}{l}\text { Less than five } \\
\text { years } \\
5-10 \text { years } \\
>10 \text { years }\end{array}$ & $\begin{array}{l}76(18.3) \\
150(36.0) \\
190(45.7)\end{array}$ \\
\hline $\begin{array}{l}\text { Do you know anyone } \\
\text { diagnosed with COVID-19 }\end{array}$ & $\begin{array}{l}\text { Yes } \\
\text { No }\end{array}$ & $\begin{array}{l}199(47.8) \\
217(52.2)\end{array}$ \\
\hline
\end{tabular}

Note: *Cancer, renal, liver disease.

Table 2 Sources of Information Towards COVID- I9 Vaccine Among Patients with Chronic Diseases Visiting in Dessie Comprehensive Specialized Hospital, Northeast Ethiopia May I-20, 202I ( $N=416)$

\begin{tabular}{|l|l|l|}
\hline $\begin{array}{l}\text { Sources of Information on } \\
\text { COVID-19 Vaccine }\end{array}$ & Frequency & Percentage \\
\hline Health professionals & 141 & 33.9 \\
Friends & 262 & 63.0 \\
Nighbours & 358 & 86.1 \\
Famil members & 330 & 79.3 \\
Newsaers & 84 & 20.2 \\
Internet & 115 & 27.6 \\
Social media & 189 & 45.4 \\
Mass media (radio and television) & 192 & 46.2 \\
\hline
\end{tabular}

replied that AstraZeneca and Covishield vaccines are currently administered against COVID-19 in Ethiopia. Furthermore, less than three-quarters 310 (74.5\%) of the respondents knew that the COVID-19 vaccine is given freely. More than three-quarters 325 (78.1\%) of the respondents knew that HCPs, patients with chrnic 
Table 3 Knowledge About COVID-19 Vaccine Among Patients with Chronic Disease Visiting in Dessie Comprehensive Specialized Hospital, Northeastern Ethiopia, May I-20, 2021

\begin{tabular}{|c|c|c|c|}
\hline \multirow[t]{2}{*}{ Items } & Yes & No & I Do Not Know \\
\hline & n (\%) & n (\%) & n (\%) \\
\hline COVID-19 can be prevented by the vaccine. & $336(80.8)$ & $55(\mid 3.2)$ & $25(6.0)$ \\
\hline AstraZeneca and Covishield are the two vaccines used in Ethiopia. & $205(49.3)$ & $78(18.7)$ & $133(32.0)$ \\
\hline The vaccine is given two times within 28 days apart & $190(45.7)$ & $81(19.5)$ & $145(34.8)$ \\
\hline The vaccine is provided for free in Ethiopia & $310(74.5)$ & $74(1.8)$ & $32(7.7)$ \\
\hline The provision of the vaccine is based on voluntary not obligatory. & $343(82.5)$ & $53(12.7)$ & $20(4.8)$ \\
\hline Healthcare professionals, chronic patients, and elders are the prioritized groups for vaccination & $325(78.1)$ & $49(11.8)$ & $42(10.1)$ \\
\hline The vaccine of COVID-19 vaccine has started & $211(50.7)$ & $124(29.8)$ & $81(19.5)$ \\
\hline
\end{tabular}

diseases, and elders are the prioritized groups to be vaccinated against COVID-19 in Ethiopia (Table 3).

\section{Attitude of Chronic Patients Towards COVID- 19 Vaccine}

Less than two-thirds 298 (61.6\%) of the respondents had a positive attitude towards the COVID-19 vaccine. Similarly, less than two-thirds 253 (60.8) of the respondents agreed that the COVID-19 vaccine is important for their life. lower number $170(40.9 \%)$ of the respondents agreed that the COVID-19 vaccine should be given to all populations of Ethiopia within a short time. More than half of the respondents agreed that the COVID-19 vaccine is against our tradition and culture (Table 4).

\section{Social and Political Factors of COVID-19 Vaccine Acceptance}

About a quarter 97 (23.3\%) of the respondents perceived that they were at high risk of contracting COVID-19 infection. Furthermore, over three-quarters, 345 (82.9\%) of the respondents trust the governments of Ethiopia towards the
COVID-19 vaccine. On the other hand, lower number 275 (66.1\%) of the respondents trust the public health authorities towards the COVID-19 vaccine (Table 5).

\section{Factors Associated with Willingness to Accept COVID-19 Vaccine}

The current finding revealed that less than two-thirds 247 $(59.4 \%)$ of the respondents were willing to accept the COVID-19 vaccine while the remaining 169 (40.625\%) refused to the vaccine. According to the binary logistic regression analysis, having health insurance, knowing anone diagnosed with COVID-19, knowledge, and attitude towards the COVID-19 vaccine were significantly associated with COVID-19 vaccine acceptance. Participants who had health insurance were 1.812 (95\% CI; 1.7033.059) times more likely to accept the COVID-19 vaccine than those without it. Furthermore, those who knew anone diagnosed with COVID-19 were 2.482 (95\% CI; $1.427-$ 4.317) times more likely to accept the COVID-19 vaccine than those who did not know. Respondents who had good knowledge about the COVID-19 vaccine were $6.890(95 \%$

Table 4 Attitude Towards the COVID-19 Vaccine Among Patients with Chronic Diseases visiting in Dessie Comprehensive Specialized Hospital, Northeastern Ethiopia, May I to 20, 202 I

\begin{tabular}{|c|c|c|c|}
\hline \multirow[t]{2}{*}{ Attitude Related Questions } & Agree & Neutral & Disagree \\
\hline & $\mathbf{N}(\%)$ & $\mathbf{N}(\%)$ & $\mathbf{N}(\%)$ \\
\hline Does the COVID-19 vaccine is essential for you? & $253(60.8)$ & $65(15.6)$ & $98(23.6)$ \\
\hline Do you think COVID-19 can be prevented by the vaccine? & $286(68.8)$ & $88(21.2)$ & $42(10.0)$ \\
\hline The vaccine of covid-19 should be given to all & $170(40.9)$ & $153(36.8)$ & $93(22.3)$ \\
\hline COVID-19 vaccine is against your culture. & $219(52.6)$ & $126(30.3)$ & $7 I(\mid 7.1)$ \\
\hline COVID-19 vaccine will save our time & $215(51.7)$ & $164(39.4)$ & $37(8.9)$ \\
\hline COVID-19 vaccine will save money & $234(56.3)$ & $119(28.6)$ & $63(15.1)$ \\
\hline Do you think you are susceptible to the infection of COVID-19 disease? & $211(50.7)$ & $138(33.2)$ & $67(16.1)$ \\
\hline It is not possible to reduce the incidence of COVID-19 without vaccination & $253(60.8)$ & $119(28.6)$ & $44(10.6)$ \\
\hline
\end{tabular}


Table 5 Social and Political Factors Affecting COVID-19 Vaccine Acceptance Among Patients with Chronic Diseases Attending Dessie Comprehensive Specialized Hospital, Northeastern Ethiopia, May I to 20, 202I

\begin{tabular}{|l|l|l|l|}
\hline Variables & Category & Frequency & Percentage \\
\hline $\begin{array}{l}\text { Self-reported } \\
\text { perception risk of } \\
\text { COVId-19 }\end{array}$ & $\begin{array}{l}\text { Low risk } \\
\text { High risk }\end{array}$ & $\begin{array}{l}319 \\
97\end{array}$ & $\begin{array}{l}76.7 \\
23.3\end{array}$ \\
\hline $\begin{array}{l}\text { Trust in the } \\
\text { government }\end{array}$ & Yes & 345 & 82.9 \\
\hline No & 71 & 17.1 \\
authorities & Yes & 275 & 66.1 \\
\hline $\begin{array}{l}\text { Trust on vaccine } \\
\text { manufacturer }\end{array}$ & Yes & 141 & 33.9 \\
\hline
\end{tabular}

CI; 3.900-120.17) times more likely to accept the COVID19 vaccine than those with poor knowledge. Finally, Participants with a positive attitude toward the COVID19 vaccine were 7.725 (95\% CI: 4.024-14.830) times more likely to accept the COVID-19 vaccine than those with a negative attitude (Table 6).

\section{Discussion}

Institution-based cross-sectional study design was conducted among patients with chronic disease visiting Dessie Comprehensive Specialized Hospital from May 1-20, 2021. The objective of the study was to assess the acceptance of the COVID-19 vaccine and determinant factors. COVID-19 vaccines have been launched as the perfect solution for bringing the pandemic of COVID-19 to an end in the world. Several countries across the world have approved specific vaccines for use in Ethiopia vaccination programs against the disease of COVID-19. ${ }^{23}$ For better implementation of the program, knowledge, and attitudes towards the COVID-19 vaccine is critical to understand the epidemiological dynamics of disease control, effectiveness, compliance, and success of the vaccination program. But vaccine hesitancy is one of the most significant barriers to the successful implementation of the programs. ${ }^{44}$ Therefore, vaccine acceptance have a decisive role in successful control of the COVID-19 pandemic. $^{45}$

Herd immunity is necessary to control the transmission of the pathogen which is dependent on the basic reproductive number for that infectious disease. The latest estimates on COVID-19 pointed out a range of $60-75 \%$ of the population should be vaccinated to halt the transmission of the disease to develop herd immunity. ${ }^{46}$ The finding of the present study revealed that less than two-thirds $(59.4 \%)$ of the respondents were willing to be vaccinated against the COVID-19 vaccine which was lower than the vaccination level required for the development of herd immunity. ${ }^{46}$ This finding was consistent with the finding in South Africa, ${ }^{47}$ Ethiopia $(62.6 \%),{ }^{13}$ in the Arab world (62.4\%). ${ }^{20}$ The finding of the study was higher than the findings in Pakistan (37.80\%), ${ }^{42}$ Ethiopia $(46.1 \%),{ }^{48}$ Ethiopia $(31.4 \%),{ }^{49} 16$ countries across the continent $(52.0 \%),{ }^{50}$ Nigeria $(50.2 \%),{ }^{51}$ USA $(36 \%),{ }^{52}$ Ethiopia (45.5\%), ${ }^{23}$ Turkey (29.2\%). ${ }^{53}$ On the contrary, it was lower than the finding in Canada $(80.9 \%),{ }^{54}$ Mexico and India (80\%), ${ }^{50}$ China $(91.3 \%),{ }^{36}$ Italy $(67 \%),{ }^{55}$ low and middle-income countries $(76.4 \%),{ }^{56}$ Colombia $(77.0 \%),{ }^{57}$ India $(78.6 \%),{ }^{28}$ India $(79 \%),{ }^{44}$ Bangladesh $(74.5 \%){ }^{58}$ The low prevalence of vaccine acceptance may be due to the fact that the novelty COVID-19 disease. Hence, there may be mistrust and negative beliefs regarding the vaccine, lack of trust in the existing healthcare system, and information gaps mainly in LMIC countries. The acceptance of COVID-19 vaccine can be increased when a safe and effective vaccine is available freely or with a minimum cost. The low rate of vaccine acceptance in this high risk groups may have an adverse effects. ${ }^{58}$ Hence, the provision of educational resources to equip Healthcare workers about the safety, importance of vaccination, and negative implication of refusing the vaccine should be implemented to improve the acceptance rate of the COVID-19 vaccine. ${ }^{14}$

Reluctance to receive these vaccines may be driven by doubts about immediate and long-term safety and efficacy, lack of trust in the development process of the vaccine, as well as background historical vaccine apathy in minority populations. ${ }^{14}$ In the current finding, the presence of health insurance, knowing anyone who has been diagnosed with COVID-19, knowledge, and attitude towards COVID-19 vaccine were factors for the acceptance of the COVID-19 vaccine among the participants. Participants who knew anyone diagnosed with COVID-19 infection were one of the factors affecting COVID-19 vaccine acceptance which was consistent with the study finding in Libya, ${ }^{40}$ Ethiopia $^{23,48}$ and China. ${ }^{59}$ The finding of the study suggested that as there is a perception that the infection of COVID-19 is not in a real event in the world.

Furthermore, participants who had health insurance showed a significantly higher acceptance rate of COVID19 vaccines which was in line with the findings in the 
Table 6 Factors Associated with Willingness to Accept the COVID-19 Vaccine Among Patients with Chronic Diseases Visiting Dessie Comprehensive Specialized Hospital, Northeastern Ethiopia, May I-20, 202 I

\begin{tabular}{|c|c|c|c|c|c|c|}
\hline \multicolumn{2}{|l|}{ Variable } & \multicolumn{2}{|c|}{ Willingness } & \multirow{4}{*}{$\begin{array}{c}\text { COR }(95 \% \mathrm{Cl}) \\
1.393\left(\begin{array}{c}0.937-2.071 \\
\mathrm{I}\end{array}\right.\end{array}$} & \multirow{4}{*}{$\begin{array}{c}\text { AOR }(95 \% \mathrm{Cl}) \\
\mathrm{I} .525\left(\begin{array}{c}0.889-2.587) \\
\mathrm{I}\end{array}\right.\end{array}$} & \multirow{4}{*}{\begin{tabular}{|} 
P-value \\
0.117
\end{tabular}} \\
\hline & & \multirow{3}{*}{$\begin{array}{c}\text { Yes } \\
118 \\
129\end{array}$} & \multirow{3}{*}{$\begin{array}{c}\text { no } \\
67 \\
102\end{array}$} & & & \\
\hline Sex & Male & & & & & \\
\hline & Female & & & & & \\
\hline \multirow[t]{3}{*}{ Marital status } & Single & 64 & 26 & I & I & \\
\hline & Married & 176 & 136 & $0.526(0.265-2.256)$ & $1.286(0.296-5.586)$ & 0.737 \\
\hline & Widowed & 7 & 7 & $0.406(0.130-1.273)$ & $0.596(0.126-2.818)$ & 0.514 \\
\hline \multirow[t]{3}{*}{ Religion } & Orthodox & 117 & 57 & $0.988(0.475-2.058)$ & $1.644(0.625-4.326)$ & 0.314 \\
\hline & Muslims & 103 & 99 & $0.5 .07(0.4752 .058)$ & $1.644(0.625-4.326)$ & $<0.0001$ \\
\hline & Protestant & 27 & 13 & I & 1 & \\
\hline \multirow[t]{2}{*}{ Health insurance } & Yes & 136 & 76 & $1.499(1.012-2.222)$ & $1.812(1.703-3059)$ & 0.026 \\
\hline & No & III & 93 & I & I & \\
\hline \multirow[t]{2}{*}{ Vaccination history } & Yes & 126 & 75 & $1.305(0.88 I-1.933)$ & $1.263(0.750-2.126)$ & 0.380 \\
\hline & No & $|2|$ & 94 & 1 & 1 & \\
\hline \multirow[t]{2}{*}{ Know diagnosed with covid-19 } & Yes & 129 & 70 & $1.546(1.042-2.295)$ & $2.482(1.427-4.317)$ & 0.001 \\
\hline & No & 118 & 99 & I & I & \\
\hline \multirow[t]{2}{*}{ Trust the gov't of Ethiopia } & Yes & 213 & 132 & $1.756(1.05 I-2.935)$ & $1.322(0.653-2.675)$ & 0.438 \\
\hline & No & 34 & 37 & I & I & \\
\hline \multirow[t]{2}{*}{ Risk on COVID-19 } & Low risk & 184 & 136 & 1 & 1 & \\
\hline & High risk & 64 & 33 & $1.441(0.896-2.138)$ & $1.355(0.722-2.543)$ & 0.344 \\
\hline \multirow[t]{2}{*}{ Knowledge } & Poor & 40 & 115 & I & I & \\
\hline & Good & 207 & 54 & $11.021(6.901-17.600)$ & $6.890(3.900-12.170)$ & $<0.0001$ \\
\hline \multirow[t]{2}{*}{ Attitude } & Negative & 24 & 94 & 1 & 1 & \\
\hline & Positive & 223 & 75 & II.646 (6.930-19.569) & 7.725 (4.024-14.830) & $<0.0001$ \\
\hline
\end{tabular}

USA $^{52}$ and China. ${ }^{60}$ There was a wide range of acceptance rates among participants; those who live in High-Income countries had the highest acceptance rate $(70.2 \%)$, whereas those who live in LMIC had the lowest acceptance rate $(57.4 \%){ }^{20}$ But, according to the report of the Ethiopian ministry of health, the COVID-19 vaccine is given for free for Ethiopians. Therefore, HCps should work in enhancing the awareness of the population mainly for high-risk groups such as patients with chronic disease and elderly groups as the vaccine of COVID-19 is given freely for all Ethiopians.

Furthermore, participants who had good knowledge towards COVID-19 vaccine were another factor of the acceptance of the COVID-19 vaccine which was consistent with the findings in Pakistan, ${ }^{42}$ Ethiopia, ${ }^{13}$ and the USA. $^{61}$ Therefore, from this study we can clearly understand we are still in the backward position towards COVID-19 vaccine awareness creation since less than two-thirds of the participants had good knowledge of the vaccine. Lastly, respondents who had a positive attitude towards the COVID-19 vaccines had a significantly higher acceptance rate of the COVID-19 vaccine which was supported by the findings in South Africa, ${ }^{47}$ Ethiopia, ${ }^{48}$ and the USA. ${ }^{60}$ The current finding clearly showed that continuous awareness promotion on the necessity of the COVID-19 vaccine should be undertaken utilizing various information dissemination methods.

Less than two-thirds $(62.7 \%)$ of the respondents had a good knowledge towards the COVID-19 vaccination which was lower than the finding in Ethiopia (74\%), ${ }^{13}$ China (80.7\%). ${ }^{59}$ This low level of knowledge towards the vaccine may be attributed due to the change in the target population, age, educational status and background, commitment of the healthcare authorities towards the disease and its vaccines, opportunity to use different sources of information towards COVID-19 vaccines. Less than 
three-quarters $(71.6 \%)$ of the participants had a positive attitude towards the COVID-19 vaccine which was consistent with the finding in China $(70.07 \%) .{ }^{59}$ The finding of the present study was higher than with the finding in Ethiopia (44\%) ${ }^{13}$ but lower than the finding in Bangladesh $(78 \%) .{ }^{9}$ The possible reason for this variation may be due to the change in risk perception towards COVID-19 and vulnerability to different diseases due to their poor immunity status, target populations.

Furthermore, less than two-thirds of the study participants agreed that the COVID-19 vaccine is essential for controlling the transmission of the disease which was higher than the study finding in Ethiopia. ${ }^{48}$ This variation may be explained due to the difference in the target population, health status, risk perception towards COVID-19, and immunity status of the participants. Besides, a similar number of respondents $60.8 \%$ agreed that the incidence of COVID-19 may not be reduced without improving the vaccination coverage. This finding was higher than the study in Ethiopia (17.1\%). ${ }^{49}$ The possible reason for this variation may be due to the change in study period, variation in the target population.

\section{Limitation of the Study}

The current study has certain limitations. The use of crosssectional study design which is the snapshot that is based on the principles of single-time visit and response. Furthermore, the use non probability sampling technique may be taken as another limitation of the study; hence generalization is difficult. Finally, the use of self-reported responses may lead to the development of social desirability bias.

\section{Conclusion}

The rapid development of the COVID-19 vaccine might have a great contribution to the emergence of concerns particularly for high-risk groups such as individuals with chronic diseases. Generally, the acceptance of the COVID-19 vaccine among the participants was low. The use of health insurance, knowing anyone diagnosed with COVID-19 infection, knowledge, and attitude towards the COVID-19 vaccine were factors of the acceptance of the COVID-19 vaccine. Hence, promotion of COVID-19 Vaccine should be done preferably by a trusted, centralized source of information like religious and political leaders. Healthcare professionals should conduct continuous awareness creation campaigns especially targeting the populations at a higher risk of the disease about the importance of the COVID-19 vaccine, safety, and its efficacy. Further studies like longitudinal and qualitative studies should be conducted to identify additional barriers to vaccine acceptance particularly in high-risk groups.

\section{Abbreviations}

$\mathrm{AOR}$, adjusted odd ratio; $\mathrm{COR}$, crude odd ratio; $\mathrm{CI}$, confidence interval; COVID-19, Coronavirus disease 2019; LMIC, Low and Middle Income; SARS COV-2, Severe Acute Respiratory Syndrome COV 2; USA, United State of America; WHO, World Health Organization.

\section{Data Sharing Statement}

The datasets used and/or analyzed during the current study are available from the corresponding author on reasonable request.

\section{Acknowledgment}

The authors would like to express their deep gratitude to Wollo University, College of Medicine and Health Sciences for providing the necessary material to conduct the study. The authors also want to extend their pleasure to Dessie Comprehensive Specialized Hospital officials for their permission to conduct this study. Study subjects were also acknowledged for their willingness to participate in the study. Finally, the data collectors and supervisors were also appreciated for their commitment.

\section{Disclosure}

The authors declare that they have no conflicts of interest in this work.

\section{References}

1. Tran VD, Pak TV, Gribkova EI, et al. Determinants of covid-19 vaccine acceptance in a high infection-rate country: a cross-sectional study in Russia. Pharm Pract. 2021;19(1):1-9.

2. Elhadi M, Msherghi A, Alkeelani M, et al. Assessment of healthcare workers' levels of preparedness and awareness regarding COVID-19 infection in low-resource settings. Am J Trop Med Hyg. 2020;103 (2):828. doi:10.4269/ajtmh.20-0330

3. Saqlain M, Munir MM, Ur Rehman S, et al. Knowledge, attitude, practice and perceived barriers among healthcare professionals regarding COVID-19: a Cross-sectional survey from Pakistan. Occup Environ Health. 2020;105(3):419-423.

4. Chowdhury S, Chakraborty PP. Universal health coverage - there is more to it than meets the eye. J Fam Med Prim Care. 2017;6 (2):169-170. doi:10.4103/jfmpc.jfmpc_13_17

5. Al-Hanawi MK, Angawi K, Alshareef N, et al. Knowledge, attitude and practice toward COVID-19 among the public in the Kingdom of Saudi Arabia: a Cross-Sectional Study. Front Public Health. 2020;8 (May). doi:10.3389/fpubh.2020.00217

6. Iannone P, Castellini G, Coclite D, et al. The need of health policy perspective to protect healthcare workers during COVID-19 pandemic. A GRADE rapid review on the effectiveness of the N95 respirator. PLoS One. 2020;15 (6):1-13. doi:10.1371/journal.pone.0234025 
7. Nallani VRR, Nadendla RR, Kavuri NSS. Knowledge, attitude, and practice among health care professionals regarding COVID-19 and barriers faced by health care professionals in South India. Int J Community Med Public Health. 2020;7(9):3450. doi:10.18203/ 2394-6040.ijcmph20203906

8. Worldometer report COVID-19 cases in the world; 2021. Available from: https://www.worldometers.info/coronavirus/world. Accessed June 09, 2021.

9. Islama $\mathrm{S}$, Siddiquea $\mathrm{AB}$, Aktera $\mathrm{R}$, et al. Knowledge, attitudes and perceptions towards COVID-19 vaccinations: a cross-sectional community survey in Bangladesh. medRxiv. 2021. doi:10.1101/ 2021.02.16.212518022021

10. Lone SA, Ahmad A. COVID-19 pandemic - an African perspective. Emerg Microbes Infect. 2020;9(1):1300-1308.

11. Baye K. COVID-19 Prevention Measures in Ethiopia Current Realities and Prospects. The Federal Democratic Republic of Ethiopia Policy Studies Institute; 2020.

12. Worldometer report COVID-19 cases in Ethiopia. 2020. Available from: https://www.worldometers.info/coronavirus/country/Ethiopia. Accessed June 9, 2021.

13. Abebe H, Shitu S, Mose A. Understanding of COVID-19 vaccine knowledge, attitude, acceptance, and determinates of COVID-19 vaccine acceptance among adult population in Ethiopia. Infect Drug Resist. 2021;14:2015-2025. doi:10.2147/IDR.S312116

14. Famuyiro TB, Ogunwale A, Bordes JD, Raji M. COVID-19: perceived infection risk and barriers to uptake of Pfizer-BioNTech and moderna vaccines among community healthcare workers. $J$ Racial Ethn Health Disparities. 2021. doi:10.1007/s40615-021-01093-6

15. Hoque AM, Alam AM, Hoque M, Hoque ME, Van Hal G. Knowledge, attitude and practice towards CoVID-19 of pregnant women at primary health care facility in South Africa. Eur J Med Res. 2021;3(1):50-55. doi:10.24018/ejmed.2021.3.1.654

16. Kebede Y, Yitayih Y, Birhanu Z, Mekonen S, Ambelu A, Tu W-J. Knowledge, perceptions and preventive practices towards COVID-19 early in the outbreak among Jimma university medical center visitors, Southwest Ethiopia. PLoS One. 2020;15(5):1-15. doi:10.1371/journal.pone. 0233744

17. Danhieux K, Buffel V, Pairon A, et al. The impact of COVID-19 on chronic care according to providers: a qualitative study among primary care practices in Belgium. BMC Fam Pract. 2020;21(1):255. doi:10.1186/s12875-020-01326-3

18. Belete ZW, Berihun G, Keleb A, et al. Towards COVID-19 and associated factors among adult hospital visitors in South Gondar. PloS One. 2021;16(5):e0250145. doi:10.1371/journal.pone.0250145

19. Troiano G, Nardi A. Vaccine hesitancy in the era of COVID-19. Public Health. 2021;194:245-251. doi:10.1016/j.puhe.2021.02.025

20. Kaadan MI, Abdulkarim J, Chaar M, Zayegh O, Keblawi MA. Determinants of COVID-19 vaccine acceptance in the Arab world: a cross-sectional study. Glob Health Res Policy. 2021;6(1):23. doi:10.1186/s41256-021-00202-6

21. Machingaidze S, Wiysonge CS. Understanding COVID-19 vaccine hesitancy. Nat Med. 2021:1-2. Available from: www.nature.com/ naturemedicine.

22. Fisher KA, Bloomstone SJ, Walder J, Crawford S, Fouayzi H, Mazor M. Attitudes toward a potential SARS-CoV-2 Vaccine. Ann Intern Med. 2020;173(12):964-973. doi:10.7326/M20-3569

23. Mesele M. COVID-19 vaccination acceptance and its associated factors in Sodo Town, Wolaita Zone, Southern Ethiopia: Cross-Sectional Study. Infect Drug Resist. 2021;14:2361-2367. doi:10.2147/IDR.S320771

24. Yohannes M. Ethiopia plans to vaccinate $20 \%$ population in 2021. Anadolu Agency website. 2021:1-3. Available from: https://www.aa. com.tr/en/africa/ethiopia-plans-to-vaccinate-20-population-in-2021/ 2133346. Accessed July 30, 2021.
25. Handebo S, Wolde M, Shitu K, Kassie A, Wang Z. Determinant of intention to receive COVID-19 vaccine among school teachers in Gondar City, Northwest Ethiopia. PLoS One. 2021;16(6):e0253499. doi:10.1371/journal.pone. 0253499

26. Green MS, Abdullah R, Vered S, Nitzan D. A study of ethnic, gender and educational differences in attitudes toward COVID-19 vaccines in Israel implications for vaccination implementation policies. Isr J Health Policy Res. 2021;10(1):26. doi:10.1186/s13584-021-00458-w

27. Pierre V, Dimitri S, Nicolas D, et al. Attitudes of healthcare workers towards COVID-19 vaccination: a survey in France and French-speaking parts of Belgium and Canada, 2020. Euro Surveill. 2021;26(3):2002047. doi:10.2807/1560-7917.ES.2021.26.3.2002047

28. Jacob J, Stephen S, Issac A, et al. Determinants of willingness for COVID-19 vaccine: implications for enhancing the proportion of vaccination among Indians. Cureus. 2021;13(5):e15271. doi:10.7759/cureus. 15271

29. Guangul BA, Georgescu G, Osman M, et al. Healthcare workers attitude towards SARS-COVID-2 vaccine, Ethiopia. Glob $J$ Infect Dis Clin Res. 2021;7(1):043-048. doi:10.17352/2455-5363.000045

30. Paul E, Steptoe A, Fancourt D. Attitudes towards vaccines and intention to vaccinate against COVID-19: implications for public health communications. Lancet Reg Health. 2021;1:100012. doi:10.1016/j.lanepe.2020.100012

31. Elharake JA, Galal B, Alqahtani SA, et al. COVID-19 vaccine acceptance among health care workers in the Kingdom of Saudi Arabia. Int $J$ Infect Dis. 2021;109:286-293. doi:10.1016/j. ijid.2021.07.004

32. Mannan AK, Farhana KM. Knowledge, attitude and acceptance of a COVID-19 vaccine: a Global Cross-Sectional Study. Munich Personal RePEc Archive; 2020. Available from: https://mpra.ub.unimuenchen.de/105236/. Accessed July 30, 2021.

33. Lin Y, Hu Z, Zhao Q, Alias H, Danaee M, Wong LP. Understanding COVID-19 vaccine demand and hesitancy: a nationwide online survey in China. PLoS Negl Trop Dis. 2020;14(12):e0008961. doi:10.1371/journal.pntd.0008961

34. Salali GD, Uysal MS. COVID-19 vaccine hesitancy is associated with beliefs on the origin of the novel coronavirus in the UK and Turkey. Psychol Med. 2020;1-3. doi:10.1017/S0033291720004067

35. Freeman D, Loe B, Chadwick A, et al. COVID-19 vaccine hesitancy in the UK: the Oxford coronavirus explanations, attitudes, and narratives survey (Oceans) II. Psychol Med. 2021:1-15. doi:10.1017/ S0033291720005188

36. Wang J, Jing R, Lai X, et al. Acceptance of COVID-19 vaccination during the COVID-19 pandemic in China. Vaccines. 2020;8 (3):482.

37. Jaramillo-Monge J, Obimpeh M, Vega B, et al. COVID-19 vaccine acceptance in Azuay Province, Ecuador: a Cross-Sectional Online Survey. Vaccines. 2021;9(6):678. doi:10.3390/ vaccines 9060678

38. Vignier N, Brureau K, Granier S, et al. Attitudes towards the COVID-19 vaccine and willingness to get vaccinated among healthcare workers in French Guiana: the influence of geographical origin. Vaccines. 2021;9(6):682. doi:10.3390/vaccines 9060682

39. Alle YF, Oumer KE. Attitude and associated factors of COVID-19 vaccine acceptance among health professionals in debre tabor comprehensive specialized hospital, North Central Ethiopia; 2021: a cross-sectional study. Indian Virol Soc. 2021;32(2):1-7. doi:10.1007/s13337-021-00708-0

40. Elhadi M, Alsoufi A, Alhadi A, et al. Knowledge, attitude, and acceptance of healthcare workers and the public regarding the COVID-19 vaccine: a cross-sectional study. BMC Public Health. 2021;21:1-21.

41. Suresh A. Public awareness and acceptance of COVID-19 vaccine: an online cross-sectional survey, conducted in the first phase of vaccination drive in India. doi:10.21203/rs.3.rs-324238/v1 
42. Maraqa B, Nazzal Z, Rabi R, Sarhan N, Al-shakhra K, Al-Kaila M. COVID-19 vaccine hesitancy among health care workers in Palestine: a call for action. Prev Med. 2021;149(May):106618. doi:10.1016/j.ypmed.2021.106618

43. Belingheri M, Roncalli M, Riva MA, Paladino ME, Teruzzi CM. COVID19 vaccine hesitancy and reasons for or against adherence among dentists. J Am Dent Assoc. 2021. doi:10.1016/j.adaj.2021.04.020

44. Bhartiya S, Kumar N, Singh T, Murugan S, Rajavel S, Wadhwani M. Knowledge, attitude and practice towards COVID-19 vaccination acceptance in West India. Int $J$ Community Med Public Health. 2021;8(3):1170-1176. doi:10.18203/2394-6040.ijcmph20210481

45. Randolph HE, Barreiro LB. Understanding COVID-19. Immunity. 2020;152(5):736-741.

46. Sallam M. COVID-19 vaccine hesitancy worldwide: a concise systematic review of vaccine acceptance rates. Vaccines. 2021;9(2):160. doi:10.3390/vaccines9020160

47. Hoque AM, Buckus S, Hoque M, Hoque ME, Van Hal G. COVID-19 vaccine acceptability among pregnant women at a primary health care facility in Durban, South Africa. Eur J Med Health Sci. 2020;2(5):1-6.

48. Zewude B, Habtegiorgis T. Willingness to take COVID-19 vaccine among people most at risk of exposure in Southern Ethiopia. Pragmat Obes Res. 2021;12:37-47. doi:10.2147/POR.S313991

49. Belsti Y, Gela YY, Akalu Y. Willingness of Ethiopian population to receive COVID-19 vaccine. $J$ Multidiscip Healthc. 2021;14:1233-1243. doi:10.2147/JMDH.S312637

50. Skjefte M, Ngirbabul M, Akeju O, et al. COVID - 19 vaccine acceptance among pregnant women and mothers of young children: results of a survey in 16 countries United States of America. Eur J Epidemiol. 2021;36(2):197-211. doi:10.1007/s10654-021-00728-6

51. Tobin EA, Okonofua M, Azeke A, Ajekweneh V, Akpede G. Willingness to acceptance a covid-19 vaccine in Nigeria: a population-based cross-sectional study. Cent Afr J Public Health. 2021;5(2):1-6.

52. Shekhar R, Sheikh AB, Upadhyay S, Singh M, Kottewar S. COVID19 vaccine acceptance among health care workers in the United States. Vaccines. 2021;9(2):119.
53. Yurttas B, Poyraz BC, Sut N, et al. Willingness to get the COVID-19 vaccine among patients with rheumatic diseases, healthcare workers and general population in Turkey: a web-based survey. Rheumatol Int. 2021;41(6):1105-1114. doi:10.1007/s00296-021-04841-3

54. Dzieciolowska S, Hamel D, Gadio S, et al. Covid-19 vaccine acceptance, hesitancy and refusal among Canadian healthcare workers: a multicenter survey. Am J Infect Control. 2021:0-21. doi:10.1016/ j.ajic.2021.04.079

55. Di Gennaro F, Murri R, Segala FV, et al. Attitudes towards Anti-SARS-CoV2 vaccination among healthcare workers: results from a national survey in Italy. Viruses. 2021;13(3):371.

56. Bono SA, Faria E, Villela DM, Siau CS, Chen WS, Pengpid S. Factors affecting COVID-19 vaccine acceptance: an international survey among low- and middle-income countries. Vaccines. 2021;9 (5):515.

57. Alvarado-socarras JL, Vesga-varela AL, Quintero-lesmes DC, et al. Perception of COVID-19 vaccination amongst physicians in Colombia. Vaccines. 2021;2:1-15.

58. Abedin M, Islam MA, Rahman FN, et al. Willingness to vaccinate against COVID-19 among Bangladeshi adults: understanding the strategies to optimize vaccination coverage. PLoS One. 2021;16(4): e0250495. doi:10.1371/journal.pone.0250495

59. Jiang N, Wei B, Lin H, Wang Y, Chaib S, Liu W. Nursing students' attitudes, knowledge and willingness of to receive the coronavirus disease vaccine: a cross-sectional study. Nurse Educ Pract. 2021:103148. doi:10.1016/j.nepr.2021.103148

60. Liu R, Zhang Y, Nicholas S, Leng A, Maitland E. COVID-19 vaccination willingness among Chinese adults under the free vaccination policy. Vaccines. 2021;2019:1-10.

61. Guidry JPD, Laestadius LI, Vraga EK, et al. Willingness to get the COVID-19 vaccine with and without emergency use authorization. Am J Infect Control. 2021;49(2):137-142. doi:10.1016/j. ajic.2020.11.018
Patient Preference and Adherence

\section{Publish your work in this journal}

Patient Preference and Adherence is an international, peer-reviewed, open access journal that focusing on the growing importance of patient preference and adherence throughout the therapeutic continuum. Patient satisfaction, acceptability, quality of life, compliance, persistence and their role in developing new therapeutic modalities and compounds to optimize clinical outcomes for existing disease states are major areas of interest for the journal. This journal has been accepted for indexing on PubMed Central. The manuscript management system is completely online and includes a very quick and fair peer-review system, which is all easy to use. Visit http:/ www.dovepress.com/testimonials.php to read real quotes from published authors. 